\title{
Biodegradation and toxicity of byproducts from the treatment of landfill leachate with hydrotalcite
}

\author{
Nair Conde de Almeida ${ }^{a, *}$, Adriano Uemura de Fariaa, Valdenilson José Alves de \\ Oliveira $^{a}$, José Silvio Govone ${ }^{b}$, Dejanira de Franceschi de Angelis ${ }^{a}$ \\ ${ }^{a}$ Department of Biochemistry and Microbiology - Institute of Biosciences - Universidade Estadual Paulista, UNESP, Av. 24A, $n^{\circ} 1515$, \\ Bela Vista, CEP 13506-900, Rio Claro, São Paulo, Brazil, Tel. +55 19 35264184; emails: ncondealmeida@yahoo.com (N.C. de Almeida), \\ aufaria@yahoo.com.br (A.U.de Faria),zito@rc.unesp.br (V.J.A.de Oliveira),dangelis@rc.unesp.br (D.F.de Angelis) \\ ${ }^{b}$ Center for Environmental Studies - CEA - Institute of Geosciences and Exact Sciences - Universidade Estadual Paulista, \\ UNESP, Av. 24A, no 1515, Bela Vista, CEP 13506-900, Rio Claro, São Paulo, Brazil, email: jsgovone@rc.unesp.br
}

Received 9 December 2017; Accepted 20 June 2018

\begin{abstract}
A B S T R A C T
Despite the toxic potential of landfill leachate, some researchers have suggested its use as fertilizer. However, high leachate concentrations can have negative impacts on the environment. Hydrotalcite has been used for the adsorption and purification of effluents. In this study, leachate in its raw and treated (sludge and leachate) forms was subjected to physicochemical, microbiological, toxicity, and biodegradability analyses. Treatment with hydrotalcite produced good results regarding the removal of conductivity $(51 \%)$, turbidity (58\%), biochemical oxygen demand in $5 \mathrm{~d}(95 \%)$, boron $(40 \%)$, ammonia $(35 \%)$, chemical oxygen demand (43\%), color (70\%), total coliforms, and Escherichia coli, but did not remove sodium or chloride and led to an increase in $\mathrm{pH}$. Treatment led to a $21.63 \%$ decrease in toxicity to Artemia sp. and a $42 \%$ decrease in toxicity to Lactuca sativa seeds. The raw and treated leachate in the soil inhibited the germination and development of $L$. sativa by $12 \%$ and $5 \%$, respectively, in comparison with the control. Landfill leachate at a concentration of $50 \mathrm{~m}^{3} /$ ha initially potentiated bacterial growth and inhibited fungal growth. The microbiota stabilized after $84 \mathrm{~d}$, except in the high concentration trials, in which the inhibition of fungal growth continued. The analyses of the landfill leachate at a concentration of $200 \mathrm{~m}^{3} /$ ha revealed that repeated fertilization could make the soil unviable for planting. The raw leachate at the two concentrations tested was toxic to Daphnia similis. The sludge at a concentration of $2.5 \%$ stimulated the growth of $L$. sativa and increased its biomass by $42 \%$ in comparison with the control, with no negative impact on the soil microbiota or toxicity to $D$. similis. The biodegradation test showed that the inoculum increased the average daily efficiency of the process. Despite the efficient biodegradation ( $50 \%$ in $24 \mathrm{~h}$ ), the toxic potential of the leachate was not eliminated. Moreover, respirometry proved not to be an effective method for the determination of the biodegradation of the sludge, since the system is influenced by the chemical characteristics of hydrotalcite.
\end{abstract}

Keywords: Landfill leachate; Hydrotalcite; Landfill leachate toxicity

\footnotetext{
* Corresponding author.
} 